\title{
Review of Alfredo Ferrarin, The Powers of Pure Reason: Kant and the Idea of Cosmic Philosophy. Chicago: University of Chicago Press, 2015
}

\author{
Ilaria D'Angelo \\ Scuola Normale Superiore \\ Pisa University \\ ilaria.dangelo22@gmail.com
}

DOI 10.1515/kjps-2016-0021

The Powers of Pure Reason by Alfredo Ferrarin is an engaging and careful study that sheds light on the most interesting and cutting-edge features of Kant's critical philosophy, in particular on Kant's notion of reason and its powers and limits, while providing us, at the same time, with an undeniably useful guide that gives a better sense of Kant's critical project.

In view of such an ambitious goal, however, Ferrarin adopts a peculiar strategy: indeed, he admits from the beginning that we face great difficulties in clarifying Kant's philosophical notions and that, most of the time, this is Kant's own fault. For instance, there seems to be no authority principle to appeal to, 'for Kant says many things and their opposite, especially about his own work' (p.22). Moreover, when it comes to the first Critique, Ferrarin talks of a "tangled web of elusive concepts whose 
superficially precise vocabulary is actually replete with complicated and puzzling distinctions hiding countless ambiguities, oscillations, and occasional contradictions" (p.3).

Thus at first we cannot but wonder about the actual possibility of disentangling ourselves from this intricate web of ambiguities and oscillations. Fortunately, harsh judgments aside, the analysis proposed by Ferrarin may be pessimistic in some respects, but is far from defeatist, and essentially relies upon (and encourages) the still current possibility of facing the many obscurities and problems of Kant's philosophy. Indeed, it is by carefully outlining the 'fault lines in Kant's edifice' that readers can traverse it more effectively (p.5). And, accordingly, the keystone of Ferrarin's account of Kant's philosophy of reason rests on the idea that the defense and plausibility of Kant's thesis must go hand in hand with a discussion of the problems it might conceal (p.5).

The declared purpose of this book, namely, to help others to understand both the difficulties and the real value of Kant's philosophy (p.4), is then fulfilled, on the one hand, by criticizing ad auctoritas arguments and widespread standard interpretations of many Kantian notions, and, on the other hand, by carrying on a 'problematic and systematic investigation that delves deeper into the many questions that remain open in his [Kant's] philosophy' (p.4).

Evidently, with this book, Ferrarin does not hesitate to take into account the most relevant question of all those that remain open, which concern the idea of unity of reason, a 'palimpsest written upon many times with remnants of earlier, imperfectly erased writing' (p.5) underlying the entire critical project, and the authentic meaning of reason itself. And it is precisely in facing this challenge that it is necessary to liberate the notion of pure reason - which is a 'free power that determines its interests and pursues the ends it sets itself' (p. 29) - both from wrongful interpretations given by scholars and from the ambiguities, second thoughts, and uncertainties of Kant himself towards one of his greatest accomplishments. I shall now highlight some of Ferrarin's claims that contribute to attaining this goal. 
At the beginning of the book, the author introduces a fairly decisive and primary problem about Kant's notion of reason and its relation to other concepts such as modern rationality. Much contemporary commentary and interpretation sees Kant's reason as continuous with modern rationality, even if, the author claims, Kant himself 'brings the modern notion of reason to a crisis' (p.9). Moreover, not only is there no actual continuity between the two concepts, for Ferrarin, but the new form of reason is not a logical calculating tool or a potentially "omnipotent" tool. Even if it has legislative powers that synthesize forms, it should not be forgotten that it also sharply delimits its scope.

The investigation of Kant's notion of reason, with its complete system of laws and principles, is further elaborated by taking into consideration the tension between the two images of reason that can be found in the Critique of Pure Reason:

a) reason as an organism that grows internally (an articulated and yet unitary system);

b) reason as an architect that plans the edifice of reason's laws, a lawgiver and judge of its own laws. Regarding this matter, the author draws particular attention to reason as an activity guided by ends (with its own needs and teleology), and explores the difference between understanding and reason before coming to the following conclusion: the image of the architect, which bears comparison to the architect described by Aristotle at the beginning of the Nicomachean Ethics as 'the politician who arranges the several activities in a relation of means and ends' (p.36), is not alternative to, but supplements the image of reason as a living unity and an organism. Indeed, the relation of ends to means is one of the most relevant aspects of reason's activity in the Architectonic (p. 36), and the philosopher, accordingly, is no other than the legislator of reason who arranges and disposes in view of reason's ends (p. 36).

These claims introduce another fundamental topic of the book, namely, the intimate connection between reason's ends and its limits. Reason as a self-contained unity, which is argued to be something different from the logical completeness that pertains to a systematic unity of knowledge, does not merely aspire at contemplating itself, but wants to give an ultimate solution to the metaphysical question. And such a project 
can be fully understood only by accepting the fact that Kant's pursuit of a critique of reason and reason's self-knowledge is at the same time a pursuit of metaphysics as a science of limits. It is precisely from this point of view that Ferrarin also wants to appraise the positive meaning of limitations within Kant's critical project, and to accordingly reconsider the results of the dialectic, in particular regarding the role of reason, regulative ideas, and philosophy.

Against the conception of the negative meaning of reason's limits, which in turn relies on the widespread negative reading of the transcendental dialectic, the author basically highlights the difference between the limits of reason as a law-giving activity and our intrinsic finitude between internal and external conditions of actualization. Reason as a law-giving activity has its own inner limits, but such limits and internal articulations have also a positive role, which is that of preserving the complete system of pure reason, according to a principle of 'metaphysical sobriety' (p. 39). Thus, when reason makes the decisive discovery of its limits (thanks to critical philosophy), such a discovery does not change the fact that reason has no authority outside itself - even though it cannot erase external givenness, luck or fate. After all, we cannot forget that we are finite human beings with limited forces.

Accordingly, reason's highest end, the highest good, is not within our control; but, on the other hand, 'the powers of pure reason in its unnatural autarchy rest on the finite powers of our human nature' (p. 102), Ferrarin claims. And this means that pure reason is driven to reach its destination - which is nothing other than wisdom, the same wisdom to which philosophers aspire to - and that this highest end pertains to reason not in spite of its unreachability (given the heteronomy of our forces) but because it is the 'perfect design of a consummately rational world' (p 103). In other words, our finitude as human beings does not prevent us from having reason and, more importantly, from choosing its path, precisely because it is the path of reason that tends to the highest end.

The Powers of Pure Reason, then, among many other things, teaches us how to take limits and powers in Kant's philosophy as mirror terms that define one another (p.106) in a sort of dynamic (or maybe dialectic) dialogue. And it is from this angle that we really get to know the power 
of a priori synthesis and how it can be considered the result or effect of an internally articulated reason - which includes intuition, intellect and reason proper.

In the end, reason's ambition of going beyond itself remains the central problem of Kant's critical philosophy, but even if there are no readymade solutions, in Ferrarin's book we are offered a refreshing perspective on a relevant (and maybe neglected) aspect of the problem. Or, in other words, we find a way to come back to Kant's valuable insights on issues such as reason, rationality, finitude, and the human condition from an original and fruitful point of view.

Kant has explained us 'the urge' of the understanding to go beyond given experience. In order to face this urge, we can either accept the powers of reason to transcend nature, and rethink the importance of its comprehensive gaze in a good, positive way, with no more misunderstandings, or we can choose to hold on to a negative sense of the critical enterprise, which basically condemns anything that goes beyond the empirical use of the categories. But, in this way, as Ferrarin argues, we have to be prepared to leave behind maybe the most interesting and cutting-edge aspects of Kant's many accomplishments. 